\title{
Functional Long Circulating Single Walled Carbon Nanotubes for Fluorescent/Photoacustic Imaging-Guided Enhanced Phototherapy
}

Lisi Xie ${ }^{1, \dagger}$, Guohao Wang ${ }^{1, \dagger}$, Hao Zhou ${ }^{2}$, Fan Zhang ${ }^{1}$, Zhide Guo ${ }^{1}$, Chuan Liu ${ }^{3}$, Xianzhong Zhang ${ }^{1}$, Lei Zhu ${ }^{1,4, *}$

1. State Key Laboratory of Molecular Vaccinology and Molecular Diagnostics \& Center for Molecular Imaging and Translational Medicine, School of Public Health, Xiamen University, Xiamen, Fujian, 361005, China;

2. Key Laboratory of Industrial Ecology and Environmental Engineering, School of Food and Environmental, Dalian University of Technology, Panjin, Liaoning, 124221, China;

3. State Key laboratory of Physical Chemistry of solid Surfaces, Department of Chemistry, Xiamen University, Xiamen, Fujian, 361005, China;

4. Departments of Surgery and Radiology and Imaging Sciences, Emory University School of Medicine, Atlanta, Georgia 30322, United States.

$\dagger$ These authors contributed equally to this work.

*To whom correspondence should be addressed. Tel: (+)86-592-2880642, Fax: (+)86592-2880642; E-mail: lei.zhu@xmu.edu.cn (L.Z.) 


\begin{abstract}
:
Nanotherapeutics have been investigated for years, but only modest survival benefits were observed clinic. This is partially attributed to the short and rapid elimination of nanodrug after intravenous administration. In this study, a long circulation single wall carbon nanotube (SWCNT) complex was successfully fabricated through a new SWCNT dispersion agent, evans blue (EB). The complex was endowed with fluorescent imaging and photodynamic therapy ability by self-assembly loading an albumin coupled fluorescent photosensitizer, Chlorin e6 (Ce6) via the high affinity between EB and albumin. The yielding multifunctional albumin/Ce6 loaded EB/carbon nanotube-based delivery system, named ACEC, is capable of providing fluorescent and photoacoustic imaging of tumors for optimizing therapeutic time window. Synergistic photodynamic therapy (PDT) and photothermal therapy (PTT) were carried out as guided by imaging results at 24 hour post-injection and achieved an efficient tumor ablation effect. Compared to PDT or PTT alone, the combined phototherapy managed to damage tumor and diminish tumor without recurrence. Overall, our study presents a SWCNT based theranostic system with great promising in dual modalities imaging guided PTT/PDT combined treatment of tumor. The applications of EB on SWCNT functionalization can be easily extended to the other nanomaterials for improving their in vivo stability and circulation time.
\end{abstract}

Key words: Long circulation, Evans blue, Albumin, Carbon nanotube, Phototherapy

\title{
1. Introduction
}

Conventional cancer therapy drug delivery systems are limited by nonspecific targeting, poor drug water solubility, and rapid drug clearance[1, 2]. Nano-based carriers are attractive vehicles for drug delivery to circumvent these limitations because they offer 
lasting steady-state serum concentrations, allowing passive drug accumulation around leaky tumor vessels due to enhanced permeation and retention (EPR), which also minimizes off-target tissue toxicity[3-6]. Unfortunately, reports suggest that after intravenous injection, many nanoparticles are rapidly cleared from circulation after binding to serum proteins via opsonization[7, 8]. Moreover, nanoparticles can be engulfed by circulating macrophages or destroyed in the liver or spleen via the mononuclear phagocytic system (MPS) or the reticuloendothelial system (RES)[8-10], which significantly reduces drug delivery efficacy. Thus, better approaches for delivering nanodrugs with lasting in vivo circulation are needed[11-13]. Currently, poly-(ethylene glycol) (PEG), a flexible and hydrophilic molecule, is used to prolong nanocarrier circulation[14, 15]; however, recent studies indicate that a PEGylated nanomedicine system can induce anti-PEG IgM antibodies after an initial injection, significantly enhancing clearance of the subsequent nanoparticle administration as rapidly as non-optimized nanoparticles[16-18]. Thus, challenges remain for developing a safe and lasing drug delivery system.

In recently years, various types of near-infrared light-responsive nanomaterials, such as gold nanoparticles, carbon materials and upconversion nanomaterials, have drawn tremendous attentions for phototherapy[19-21]. Among these particles, carbon nanotubes especially single walled carbon nanotubes (SWCNTs), offered more advantages over other nanoparticles including large and uniquely shape, excellent photo-thermal concerting efficacy, high cargo loading, excellent cell penetration ability 
and strong raman signals [22-25]. It is believed that SWCNT will be a promising cancer theranostic agent with appropriate surface modification to improve the biocompatibility and tumor targetability, because unmodified SWCNTs have highly hydrophobic surfaces and are not aqueous soluble. Modifying these hydrophilic surfaces can improve water solubility and improve SWCNTs performance via linking multiple active molecules such as peptides, genes, proteins, and drugs[26-33]. Evans blue (EB), a strong hydrophilic and non-toxic biological vessel stain, that can be used to coat SWCNTs via non-covalent adsorption and increased water solubility has been reported [34]. Importantly, EB modification of SWCNTs does not break their $\pi$ network and preserves their physical properties, suggesting promise for drug loading and imaging applications[34]. In addition, EB can form stable complex with the serum albumin which is presently an FDA-approved biocompatible drug delivery carrier that can target cancer cells with the albumin receptor gp60 and SPARC[35]. It is known that albumin can prolong nanomaterial circulation[35, 36], we hypothesized that SWCNT/EB complexed to albumin could circulate longer than unmodified SWCNTs and drug accumulation would occur at target sites, for example tumors.

In this study, a novel long-circulating SWCNT-based therapeutic system was established to deliver Chlorin e6 (Ce6), a widely used photosensitizer with strong near fluorescence, for combined synergistic photodynamic therapy (PDT) and photothermal therapy (PTT). Specifically, Ce6 was encapsulated with albumin to increase its stability and hydrophilicity. Subsequence, the formed albumin/Ce6 complex was loaded onto 
the surface of EB-modified SWCNTs by exploiting the high affinity between albumin and EB. In this system, the strong optical absorbance of SWCNTs and Ce6 fluorescence allows photoacoustic (PA) and fluorescent (FL) imaging of the complex in tumors to guide PDT/PTT therapy (Scheme 1), which may improve tumor treatment efficacy without obvious side effects. Compared to single therapeutic treatment, combined PTT and PDT therapy can significantly improve treatment outcomes without recurrence. Overall, this new biocompatible delivery system allows complementary imaging modalities, a long circulation time and improved tumor accumulation for synergistic tumor PDT/PTT treatment. This simple, effective and long-circulating multifuntional SWCNTs delivery platform is ideal for targeted molecular image-guided therapy. 


\section{Materials and methods}

Materials: Albumin, Evans blue (EB), DAPI, 3-(4,5-dimethylthiazol-2-yl)-2,5diphenyltetrazolium $\quad$ bromide $\quad$ (MTT), 3,6-Di(O-acetyl)-4,5-bis[N,Nbis(carboxymethyl)aminomethyl]fluorescein, tetra-acetoxy-methyl ester (Calcein-AM) and 3,8-diamino-5-[3-(trimethylammonio)propyl]-6-phenyl phenanthridine (PI) were purchased from Sigma-Aldrich (St. Louis, MO). Ce6 was acquired from Life Science (Shanghai, China). DMEM cell culture medium, fetal bovine serum (FBS) and penicillin-streptomycin were acquired from Hyclone (Pittsburgh, PA). SWCNT (carbon (carbon as SWCNT) $>80 \%$, diameter: $0.7-1.4 \mathrm{~nm}$ ) was purchased from SigmaAldrich (St. Louis, MO).

\subsection{Preparation of albumin encapsulated Ce6 and ECNTs}

Albumin encapsulated Ce6-SWCNTs (ACEC) were prepared as follows. Briefly, 160 $\mathrm{mg}$ albumin was dissolved in $10 \mathrm{~mL}$ ultrapure water and encapsulated into $40 \mathrm{mg}$ Ce6 under high pressure homogenization (PhD Technology International, MN, USA) at 4 ${ }^{\circ} \mathrm{C}$. The product was purified by dialysis (cutoff $=100 \mathrm{kDa}$ ) against ultrapure water at room temperature for $24 \mathrm{~h}$. After freeze drying, the loading efficiency of albumin/Ce6 was calculated with analytical $\operatorname{HPLC}(\mathrm{C} 18,5 \mu \mathrm{m}, 250 \times 4.6 \mathrm{~mm})$. Meanwhile, SWCNTs $(5 \mathrm{mg})$ and $\mathrm{EB}(1 \mathrm{mg})$ were mixed in $5 \mathrm{~mL}$ deionized water and sonicated for $30 \mathrm{~min}$ on ice. Products were purified by centrifugation at $10,000 \times \mathrm{rpm}$ for $1 \mathrm{~h}$ and the dispersible SWCNT/EB complex (ECNTs) were acquired and these were purified and concentrated by ultrafiltration. 


\subsection{Preparation of ACEC self-assembly}

First, $15 \mathrm{mg}$ of albumin/Ce6 and $3 \mathrm{mg}$ ECNTs were dissolved in $10 \mathrm{~mL}$ deionized water and stirred at room temperature for $30 \mathrm{~min}$. Then, the solution was centrifuged at 10,000 rpm for $1 \mathrm{~h}$ and the ACEC supernatant was obtained. To remove unloaded albumin, the solution was added to a PD-10 column and the desired fraction was collected. To quantify loaded Ce6 in ECNT, samples were incubated in a methyl alcohol solution for 30 min to break bonds between albumin and EB. Ce6 was then released and dissolved in supernatant and measured with analytical HPLC $(\mathrm{C} 18,5 \mu \mathrm{m}, 250 \times 4.6 \mathrm{~mm})$. Ce6 released from ACEC was calculated according to the standard curve.

\subsection{Characterization of ACEC}

ACEC morphology was assessed by AFM. Samples of albumin/Ce6, ACEC and the zeta potential of free $\mathrm{Ce} 6$, albumin/Ce6, ECNTs, ACEC were measured via dynamic light scattering (DLS) using a Malvern Zeta Sizer (Malvern, England). To evaluate ACEC stability in DMEM with $10 \%$ FBS, water, PBS and FBS, samples were placed in tubes at room temperature for more than $48 \mathrm{~h}$ and, UV-Vis-NIR absorption spectra were measured. To confirm successful loading of ACEC, UV-Vis-NIR absorption spectra changes across different samples (free Ce6, albumin/Ce6, ECNTs and ACEC)

were monitored. FL intensity of free Ce6 and ACEC was measured (ex/em: 400/670).

\subsection{In vitro PTT effect}


Different samples (free Ce6, albumin/Ce6, ECNTs and ACEC) with CNTs (50 $\mu \mathrm{g} / \mathrm{mL}$ ) in $300 \mu \mathrm{L}$ Eppendorf tubes were exposed to $808 \mathrm{~nm}$ radiation $\left(0.5 \mathrm{~W} / \mathrm{cm}^{2}\right)$ for $10 \mathrm{~min}$ and thermal images were captured with an infrared thermal imaging FLIR Ax5 camera (FLIR Systems Inc., Wilsonville, OR) and quantified with BM_IR software.

\subsection{In vitro PA imaging}

Free Ce6, albumin/Ce6, and ACEC with various CNTs concentrations (200, 100, 50, 25 and $12.5 \mu \mathrm{g} / \mathrm{mL})$ were added to Eppendorf tubes $(200 \mu \mathrm{L})$ immersed at the same depth in $\mathrm{ddH}_{2} \mathrm{O}$. PA tomography for all samples was captured at $808 \mathrm{~nm}$ using Endra Nexus128 (Ann Arbor, MI).

\subsection{ROS generation}

Singlet oxygen as a reactive oxygen species (ROS) was measured according to published methods[37, 38]. Briefly, single oxygen generation of free Ce6 and ACEC at different concentrations $(1-50 \mu \mathrm{g} / \mathrm{mL})$ was assessed with 2', 7'-dichlorofluorescin diacetate (DCFH-DA) to quantify ROS. First, $0.5 \mathrm{~mL}$ of $1 \mathrm{mM}$ DCFH-DA was added to $2 \mathrm{~mL}$ of $0.01 \mathrm{M} \mathrm{NaOH}$ and the mixture was incubated at room temperature in the dark for 30 min, converting DCFH-DA to DCFH. Then, 10 mL PBS (pH 7.4) was added to neutralize the reaction. Next, samples were mixed with DCFH $(25 \mathrm{mM})$ and irradiated with an NIR laser $\left(630 \mathrm{~nm}, 0.15 \mathrm{~W} / \mathrm{cm}^{2}\right)$. FL intensity data $(520 \mathrm{~nm})$ allowed estimation of ROS. Then, we measured the effect of heat on ROS generation by exposing ACEC $(50 \mu \mathrm{g} / \mathrm{mL})$ to radiation $(808 \mathrm{~nm})$ for $10 \mathrm{~min}$ at different frequencies 
$(0.3,0.5,1,1.5 \mathrm{~W})$. Thermal images were captured and then samples were mixed with DCFH and irradiated $(630 \mathrm{~nm})$ for $5 \mathrm{~min}\left(0.15 \mathrm{~W} / \mathrm{cm}^{2}\right)$ and free Ce6 was a control. Then, UV-Vis absorption spectra of all samples were measured.

\subsection{Cell uptake}

SCC-7 cells were cultured in DMEM medium supplemented with 10\% FBS, 100 units $/ \mathrm{mL}$ penicillin and 100 units $/ \mathrm{mL}$ streptomycin at $37^{\circ} \mathrm{C}$ with $5 \% \mathrm{CO}_{2}$. To measure uptake, $5 \times 10^{4}$ SCC-7 cells were seeded on millicell EZ slides (Millipore, Billerica, MA) at $37^{\circ} \mathrm{C}$ for $24 \mathrm{~h}$. Free Ce6, albumin/Ce6 and ACEC (corresponding to $20 \mu \mathrm{g} / \mathrm{mL}$ Ce6) were incubated with cells for $6 \mathrm{~h}$ and cells were washed with PBS three times for 10 min to remove free Ce6, albumin/Ce6 or ACEC. Then, samples were fixed with $4 \%$ formaldehyde (1 mL per well) for 20 min. Next, cells were stained with DAPI and FL images were acquired under a laser scanning confocal microscope (ZEISS, Germany).

\subsection{In vitro phototherapy}

MTT assay was performed to measure cytotoxicity of ACEC. SCC-7 cells were incubated with samples $(\mathrm{Ce} 6 \simeq 1-50 \mu \mathrm{g} / \mathrm{mL})$ for $24 \mathrm{~h}$ in the dark. Cells incubated with free Ce6 under the same conditions were controls. Then, in vitro PDT, PTT and PDT/PTT and phototoxicity of ACEC at different Ce6 concentrations was measured by MTT assay. For in vitro PDT/PTT, SCC7 cells $\left(5 \times 10^{3}\right.$ cells per well $)$ were cultured in a 96-well flat-bottomed plate and incubated overnight. Then, free Ce6, ECNTs, albumin-ECNTs, albumin/Ce6 and ACEC (20 $\mu \mathrm{g} / \mathrm{mL}$ Ce6or $2.4 \mu \mathrm{g} / \mathrm{mL}$ ECNTs) were 
added and cells were incubated for $6 \mathrm{~h}$, washed with PBS three times, and fresh medium was added. Experimental groups were then exposed to NIR light $(\lambda 630 \mathrm{~nm} ; 0.15$ $\left.\mathrm{W} / \mathrm{cm}^{2}\right)$ for $1 \mathrm{~min}$ and $\lambda 808 \mathrm{~nm}\left(1 \mathrm{~W} / \mathrm{cm}^{2}\right)$ for $2 \mathrm{~min}$ and the laser covered the entire well area. Next, cells were washed with PBS and incubated for an additional $12 \mathrm{~h}$ at 37 ${ }^{\circ} \mathrm{C}$. Cells incubated in the dark without radiation were incubated under the same conditions.

Synergistic PDT/PTT effects of ACEC on SCC-7 cells were assessed with AM/PI. SCC-7 cells $\left(3 \times 10^{5}\right.$ per well $)$ were seeded in 6 -well plates and incubated overnight at $37^{\circ} \mathrm{C}$ and then medium containing free Ce6, albumin/Ce6, albumin-ECNTs and ACEC (20 $\mu \mathrm{g} / \mathrm{mL} \mathrm{Ce} 6)$ was added and incubated for $6 \mathrm{~h}$, respectively. Cells were then exposed to NIR light, washed, and fresh medium was added as depicted above. Controls were incubated under identical conditions in the dark. After an additional $4 \mathrm{~h}$ incubation, cells were stained with AM ( $4 \mu \mathrm{M}$, live cells, green fluorescence; $\lambda$ ex/em 490/515 nm) and PI solutions ( $4 \mu \mathrm{M}$, dead /late apoptotic cells, red fluorescence; $\lambda$ ex/em 490/617 nm). Cells were observed microscopically (ZEISS, Oberkochen, Germany).

\subsection{In vivo tumor imaging}

Animal experiments were conducted as approved by the Animal Care and Use Committee of Xiamen University. BALB/c nude female mice (6-8 weeks of age, 20 g) were purchased from Xiamen University Laboratory Animal Center (Xiamen, China). For in vivo fluorescent imaging, tumor-bearing female nude (18-20 g) mice were administered a suspension of $5 \times 10^{6} \mathrm{SCC}-7$ cells (sc) into the right leg. When 
tumors were $\sim 80 \mathrm{~mm}^{3}$, mice were randomly divided to four groups $(\mathrm{N}=5)$. Free $\mathrm{Ce} 6$, albumin/Ce6, ECNTs and ACEC (equals to $5 \mathrm{mg} \mathrm{Ce6/kg,} \mathrm{CNTs} 0.3 \mathrm{mg} / \mathrm{kg}$, i.v.) were administered to mice. Controls were injected with an equal volume of normal saline. Then, FL images were acquired with $\lambda_{\mathrm{ex}} 670 \mathrm{~nm}$ on a Xenogen IVIS-100 system at 0 , $2,4,6,8,12,24,48$, and $72 \mathrm{~h}$ post-injection. Signal intensity was quantified as the average of all detected photon counts from a region of interest prescribed over the tumor site and performed as tumor to muscle ratio. Mice were sacrificed after 12, 24, and $72 \mathrm{~h}$ imaging. Tumors and heart, liver, spleen, lung, kidney, brain and muscle were collected for ex vivo imaging and average signal intensity was measured. For in vivo PA imaging, mice were treated as described above. PA imaging at tumor sites was performed with an Endra Nexus128 ( $\lambda 808 \mathrm{~nm}$ ) over time 0, 2, 6, 12, 24, 48, and $72 \mathrm{~h}$.

\subsection{Blood biodistribution of ACEC}

$25 \mathrm{mg}$ ACEC was mixed with $5 \mathrm{mCi}$ of ${ }^{131} \mathrm{I}$ in the existing of $50 \mu \mathrm{L}$ Chloramine $\mathrm{T}(2$ $\mathrm{mg} / \mathrm{mL}$ in PBS) for $5 \mathrm{~min}$ at the room temperature. After that, the reaction was terminated by adding $50 \mu \mathrm{L}$ of sodium pyrosulfite $(2 \mathrm{mg} / \mathrm{mL}$ in PBS $)$. At last, free ${ }^{131} \mathrm{I}$ was removed by centrifugation and ${ }^{131} \mathrm{I}$-ACEC was obtained and freeze dryed. When SCC7 tumor grow to $80-100 \mathrm{~mm}^{3},{ }^{131}$ I-ACEC was intravenously injected at $10 \mu \mathrm{Ci}$ per mouse. At predetermined time points $(0,0.5,3,6,12,24,48,72 \mathrm{~h}), 50 \mu \mathrm{L}$ of blood sample was colleced from orbital vein. Radioactivity of blood samples were detected by Automatic Gamma Counter and analyzed. 


\subsection{In vivo phototherapy}

Animal experiments were conducted as approved by the Animal Care and Use Committee of Xiamen University. Mice $(\mathrm{N}=40)$ bearing SCC-7 tumors on right legs were randomly divided into 8 groups and administered (iv) physiological saline, free Ce6, albumin/Ce6, ECNTs, albumin-ECNTs or ACEC (5 mg/kg Ce6, $0.3 \mathrm{mg} / \mathrm{kg}$ CNTs). Treatment groups were as follows: (1) PBS without radiation; (2) PBS with radiation; (3) free Ce6 without radiation; (4) free Ce6 with radiation; (5) ACEC without radiation; (6) ACEC with radiation; (7) albumin/ECNTs without radiation; (8) albumin/ECNTs with radiation (9) albumin/Ce6 without radiation; (10) albumin/Ce6 with radiation. Then, 24 h post-injection, groups 2, 4, 6, 8 and 10 were irradiated $(\lambda 630 \mathrm{~nm} ; 0.15$ $\left.\mathrm{W} / \mathrm{cm}^{2}\right)$ for $10 \mathrm{~min}$ and $\lambda 808 \mathrm{~nm}\left(1 \mathrm{~W} / \mathrm{cm}^{2}\right)$ for $15 \mathrm{~min}$. Thermal imaging in the tumor region was recorded and tumor volume and weights were recorded every 2 days. After treatment, major organs and tumors were separated and cut into 8- $\mu \mathrm{m}$ sections with a microtome (Leica freezing microtome CM1950, Germany) for hematoxylin and eosin (H\&E) staining for subsequent histological analysis.

\subsection{Statistical analysis}

Comparisons among groups were analyzed via independent-samples one-factor ANOVA test using SPASS 17.0 software. All statistical data were obtained using a two-tailed Student's t-test and homogeneity of variance tests $(\mathrm{p}$ values $<0.05$ were considered significant). 


\section{Results and discussion}

\subsection{Preparation and characterization of ACEC}

SWCNT was chosen in ACEC system for photoacoustic imaging and phototheramal therapy, because of the strong light absorbance property and excellent light-thermal converting potency[39]. To make a water-dispersible SWCNTs suspension, EB was applied to SWCNTs (ECNTs) by high frequency sonication as previously reported[34]. Meanwhile, by encapsulation of a photosensitizer, Ce6, ACEC will provide both photothermal and photodynamic therapy abilities, which may enhance the tumor ablation efficacy as well as reducing the side effects of phototherapy. Albumin encapsulated hydrophobic Ce6 (albumin/Ce6) was prepared via high-pressure homogenization. The loading efficiency of Ce6 into albumin was measured and investigated at different ratios (Table S1). Ce6 content in ECNTs was analyzed and calculated using a UV-vis-near infrared (NIR) absorbance spectrum and HPLC (Fig.S1a and S1b). Afterwards, the albumin/Ce6 complex was loaded onto ECNT by mixing, taking advantage of the strong binding affinity between EB and albumin. To optimize the loading, different albumin/Ce6/EB/SWCNT (ACEC) with various ratios of albumin/Ce6 versus ECNT were prepared and analyzed. As shown in Table 1, 81\% albumin/Ce6 can be loaded onto ECNTs at 4:1 w/w ratio, indicating our albumin loading strategy endow ECNT high drug-loading potency. 
This optimized construction of ACEC was then analyzed by different approaches as shown in Fig. 1. Successful preparation of an albumin/Ce6 complex functionalized ECNT (ACEC) was confirmed with UV-vis-NIR spectrum. As shown in Fig.1a, a broad absorbance spectrum from SWCNT attributed to near-ultraviolet plasmon resonances of nanotubes and carbonaceous impurities was found[40, 41]. EB- and Ce6-specific absorbance peaks were observed between 600 and $700 \mathrm{~nm}$, but no specific peaks were observed in Tween-20 dispersed SWCNTs. It is also noticeable that the characteristic Soret band at $404 \mathrm{~nm}$ and the Q-band at $660 \mathrm{~nm}$ from Ce6 were quenched possibly due to the strong interactions between Ce6 and ECNTs. To evaluate the potential of ACEC in vivo applications, the formed ACEC was subjected to different physiological solutions including DMEM, FBS, PBS and water (Fig. 1b) at $37^{\circ} \mathrm{C}$ and no precipitation or obvious UV-vis-NIR spectral changes occurred. Importantly, fluorescent signal quenching effect was not observed within ACEC system compared with free Ce6 (Fig. 1c and Fig. S2), allowing FL imaging of ACEC distribution in vivo. In addition, it is known that SWCNT holds a strong photoacoustic effect, we then assessed PA signals from ACEC (Fig. 1d). As we expected, strong PA signals from ACEC were observed and no signals from albumin/Ce6 were detected, confirming that PA imaging can be used to analyze ACEC accumulation in tumors. Collectively, these in vitro data suggest that the successfully constructed ACEC is stable and is a potentially promising theranostic agent. Optical/PA imaging of ACEC can assist with monitoring ACEC distribution and offer histological information in situ. 


\subsection{Cellular targeting ability and in vitro toxicity of ACEC}

Next, cancer cellular targeting ability of ACEC was investigated using cell fluorescent staining (Fig. 2). As shown in Fig. 2a, compared with Ce6 and albumin/Ce6, ACECtreated SCC7 cells had strong cell surface fluorescent signals, indicating that ACEC could better target cancer cells and enhance the PA effect. Different from albumin dispersed SWCNT that embed SWCNT into Albumin by sonication[42], ACEC was formed by EB dispersed SWCNT binding with Albumin/Ce6 complex via simply mixing. In this way, albumin structure will not be impaired and holding more room for drug encapsulation. In addition, elevated therapeutic efficacy is expecting to be achieved because of better EPR from ACEC. In the considerate of SWCNT strong absorbance in the near-infrared (NIR) region, the photothermal effect of ACEC for thermal ablation of tumor cells were investigated. As seen from Fig. 2b and S2a, ACEC solution temperature climbed from $25{ }^{\circ} \mathrm{C}$ to $65{ }^{\circ} \mathrm{C} 5$ min after laser irradiation $(0.5$ $\mathrm{W} / \mathrm{cm}^{2}, 808 \mathrm{~nm}$ ), while the temperature decreased rapidly when the radiation source was extinguished. No significant temperature changes occurred for Ce6, albumin/Ce6 or PBS groups even with laser illumination (Fig. S3). On the other hand, because Ce6 is able to transfer photo energy to reaction oxygen species (ROS) after $630 \mathrm{~nm}$ laser irradiation, ROS generation by ACEC was measured using a commercial kit using DCFH-DA. Using this assay, fluorescent intensity is proportional to ROS. Fig.2c and S2b clearly showed that that ACEC generates similar ROS as free Ce6, suggesting that ACEC complex formation does not affect ROS generation by Ce6. Of note, when free 
Ce6 is $30 \mu \mathrm{g} / \mathrm{mL}$, fewer ROS may be self-quenched. This quenching was not observed with the ACEC complex likely because albumin/Ce6 is evenly distributed in ECNT and ROS quenching was weaker between Ce6 molecules although ROS were abundant.

It is worth to mention that heat generated during PTT may influence ${ }^{1} \mathrm{O}_{2}$ generation from Ce6 and limit the synergism of PDT and PTT. To this end, PDT and PTT sequences mediated by ACEC were assessed. We observed that ROS generated by ACEC increased with increasing temperature $\left(30-50{ }^{\circ} \mathrm{C}\right)$ after exposure to NIR laser $(630 \mathrm{~nm})$, whereas ROS decreased modestly at $65^{\circ} \mathrm{C}$, which may be due to structure destruction of Ce6 at high temperatures (Fig. S4). Therefore, to allow simultaneous PDT and PTT and avoid photothermal effects on Ce6 stability, PDT has to be initiated first and added PTT later. To ensure that irradiation induced temperature increase did not cause ACEC aggregation and degradation, ACEC stability was also investigated (Fig. S5 a and b). We saw no obvious UV-vis-NIR changes and precipitation using different irradiation strengths at different temperature (Fig. S5b, insert), suggesting ACEC is stable at high temperature $\left(30,40,48\right.$, and $\left.65^{\circ} \mathrm{C}\right)$ and SWCNT is still well dispersed.

The entry of ACEC into cells were tested by Raman imaging before moving forward. As shown in Fig. S6, enhanced SWNT Raman signals at $1590 \mathrm{~cm}^{-1}$ were detected in ACEC treated cells while no signal can be found for Ce6 treated cells, implying SWCNT facilitate Ce6 entering of cells. Next, in vitro PDT/PTT therapeutic effects of 
ACEC were studied next, as shown in Fig. S7a, SCC7 cells were treated with PBS, albumin/ECNT, albumin/Ce6 or ACEC with and without laser irradiation. No laseruntreated group revealed cytotoxicity. However, with laser irradiation, PDT/PTT was synergistic with respect to tumor cell ablation in the ACEC group compared to all other groups including those treated with PTT (albumin/ECNT: $808 \mathrm{~nm}$ laser), PDT (albumin/Ce6: $630 \mathrm{~nm}$ laser) and controls (PBS: 808 and $630 \mathrm{~nm}$ laser) and 89.9\% cells died (Fig. S7a). We confirm this effect with a fluorescent live/dead cells staining assay (Fig. S7b). Almost all cells were dead (propidium iodide, PI, red) in the combined PDT/PTT treatment group, and about $30 \%$ of cells were alive (calcein AM, green) in groups treated with PDT or PTT alone, suggesting that PDT and PTT is better for tumor ablation. To further confirm that ACEC is more efficacious for tumor ablation, cells treated with ACEC were divided into four groups: ACEC without irradiation, ACEC with irradiation (PTT only: $808 \mathrm{~nm}$ ), ACEC with irradiation (PDT only: $630 \mathrm{~nm}$ ), ACEC with laser irradiation (PTT and PDT combined: $630 \mathrm{~nm}$ and $808 \mathrm{~nm}$, respectively). Fig. 2d demonstrated that PTT and PDT together was better for reducing SCC7 cell growth and this was concentration-dependent. Thus, in vitro cytotoxicity was greater with combined PDT/PTT treatment and the ACEC system has enormous promise for tumor treatment in vivo.

\subsection{Blood circulation behavior of functionalized ACEC}


To investigate the blood circulation behavior of ACEC, albumin in ACEC was labeled by ${ }^{131}$ I. Because of the excellent stability of ACEC in physiological condition, we consider ${ }^{131} \mathrm{I}$ labeled albumin will be able to represent in vivo behavior of ACEC. 100 $\mu \mathrm{Ci}$ of ${ }^{131} \mathrm{I}$ labeled ACEC was intravenously injected into mice bearing human squamous cell carcinoma SCC7 tumor and $5 \mu \mathrm{L}$ of blood was collected at different time points for radioactive counting. The calculated $\% \mathrm{ID} / \mathrm{g}$ (percentage of injected dose per gram) in blood versus time post injection were considered indication of the ACEC behavior in blood circulation. It has to note that blood circulation time was defined as the time over which the ACEC level reduced to less than $5 \% \mathrm{ID} / \mathrm{g}$ in blood [43, 44]. As shown in Fig. 3, ACEC exist in blood circulation for up to $48 \mathrm{~h}$, suggesting that EB functionalization significantly extent the blood half-life of SWCNT. It is believed that the prolonging circulation in blood provides more possibility of SWCNT/EB carried drugs accumulation in tumors and therefore improve the therapeutic efficiency.

\subsection{In vivo PA and FL imaging of ACEC}

FL and PA imaging are high-resolution, non-radioactive imaging modalities with different advantages[45]. For example, FL can image whole bodies of live animals and illuminate probe distribution[46]. PA imaging offers higher resolution and deeper imaging depth than FL imaging and can be used to see blood vessel distribution and probes accumulation in situ, especially tumors[47]. Therefore, combining FL and PA imaging will offer more information for investigation of in vivo probe behaviors and 
can guide therapeutic actions to optimize treatment. Here, ACEC was designed to be both a FL and PA imaging agent.

First of all, to optimize ACEC for tumor treatment, we measured ACEC accumulation in tumors in real time with in vivo fluorescent and PA imaging. SCC7 tumor-bearing mice were intravenously administrated with free $\mathrm{Ce} 6$, albumin/Ce6 or ACEC when tumors volume reached $\sim 80 \mathrm{~mm}^{3}$. FL and PA images were acquired at the indicated time points as shown in Fig.4a and b. In Ce6 received groups, fluorescent signals can be seen distributed mostly in the liver $8 \mathrm{~h}$ post-treatment and disappeared $24 \mathrm{~h}$ postinjection. In contrast, fluorescent images from tumor regions gradually strengthened over time and peaked $(\mathrm{T} / \mathrm{M}$ ratio $=7.83 \pm 0.31)$ at $24 \mathrm{~h}$ post-treatment in the ACEC group and gradually eliminated, indicating that ACEC circulated for a greater duration and accumulated more than the free $\mathrm{Ce} 6$ and albumin/Ce6. PA imaging confirmed that ACEC was taken up in the same manner (Fig. 4c and d). The PA signal in the tumor area increased over time after ACEC treatment and decreased after $24 \mathrm{~h}\left(\mathrm{P}_{\mathrm{A}} / \mathrm{P}_{0}=4.76\right.$ $\pm 0.16)$ after treatment. No obvious PA signal changes were noted in mice treated with free Ce6 due to a lack of targeting activity.

Because ACEC is physiologically stable, we thought that FL signals from ACEC may be helpful for assessing ACEC in vivo. Thus, mice from different treatment groups were sacrificed at different time points after ACEC, albumin/Ce6 or free Ce6 administration and major organs were collected and imaged (Fig. S8). Free Ce6 was observed 
distributed evenly within the mouse body because it lacked targeting specificity, and some Ce6 accumulated in tumors $12 \mathrm{~h}$ after treatment but this was due to the high vascularity of the tumor and livers and kidneys had some Ce6 due to its hydrophobicity. Ce6 was rapidly eliminated as well. Mice treated with ACEC had significant uptake that peaked 24 after treatment and FL signals subsequently decreased. The tumor-tomuscle ratio of ACEC was $5.4 \pm 0.82$ at $24 \mathrm{~h}$ post-treatment confirming tumor accumulation. Also, livers, kidneys and lungs took up ACEC, likely due to metabolic pathways within these organs. Similar results were noted with PA imaging and in vivo and ex vivo data confirmed that ACEC had tumor-specific accumulation (peaked at 24 h) and circulated for a greater duration than Ce6 and albumin/Ce6. Thus, we applied PDT/PTT for tumor ablation at $24 \mathrm{~h}$ post-ACEC-treatment.

\subsection{In vivo combination therapy}

Considering the quick oxygen consumption and pre-existing hypoxia microenvironment in tumor, therapeutic efficacy of PDT is always limited and unsatisfied. On the other hand, PTT is prone to induce heat-shock protein (HSP) facilitated thermotolerance in cancer cells[48], which can significantly limit the application of PTT. Therefore, a synergistic phototherapy approach will overcome the deficiencies of PDT and PTT. The tumor ablation efficacy of ACEC was finally investigated in SCC7 tumor-bearing mice model. After the tumor volume growth to 80 $\mathrm{mm}^{3}$, mice were randomly divided into eight groups: PBS with/without radiation; Ce6 
with/without radiation; albumin/Ce6 with/without radiation; albumin/ECNT with/without radiation; and ACEC with/without radiation. Mice in each treatment group were anesthetized and imaged to observe tumor growth every five days (Fig.S9). Photothermal effects were measured with an infrared thermal camera (Fig. 5 a and b). Mice in groups that obtained PDT and PTT treatment received PDT first to ensure that PTT did not modify the chemical structure or the encapsulation of the photosensitizer. Fig. 5a shows that tumors treated with ACEC and irradiated $(808 \mathrm{~nm})$ increased in temperature with time as indicated $\left(34.21^{\circ} \mathrm{C}, 37.47^{\circ} \mathrm{C}, 40.41^{\circ} \mathrm{C}, 47.8^{\circ} \mathrm{C}, 52.91^{\circ} \mathrm{C}\right.$ and $53.45^{\circ} \mathrm{C}$ ), which is sufficient to ablate cancer cells. Similar temperature increases occurred in the albumin/ECNT group $\left(32.35^{\circ} \mathrm{C}, 36.76^{\circ} \mathrm{C}, 38.27^{\circ} \mathrm{C}, 43.71^{\circ} \mathrm{C}, 47.85^{\circ} \mathrm{C}\right.$, $49.1^{\circ} \mathrm{C}$ ) at indicated time points. No detectable temperature changes occurred for PBS$\left(33.33{ }^{\circ} \mathrm{C}, \quad 35.65^{\circ} \mathrm{C}, 37.21^{\circ} \mathrm{C}, 37.26^{\circ} \mathrm{C}, 37.9^{\circ} \mathrm{C}, 38.27^{\circ} \mathrm{C}\right)$, Albumin/Ce6- $\left(33.18^{\circ} \mathrm{C}\right.$, $\left.36.24^{\circ} \mathrm{C}, 37.06^{\circ} \mathrm{C}, 36.9^{\circ} \mathrm{C}, 37.06{ }^{\circ} \mathrm{C}, 37.04{ }^{\circ} \mathrm{C}\right)$ or Ce6- $\left(32.32{ }^{\circ} \mathrm{C}, 35.18{ }^{\circ} \mathrm{C}, 37.59{ }^{\circ} \mathrm{C}\right.$, $\left.38.50{ }^{\circ} \mathrm{C}, 38.63{ }^{\circ} \mathrm{C}, 38.77{ }^{\circ} \mathrm{C}\right) \quad$ treated animals, suggesting that ACEC is an effective in vivo PTT agent for tumor ablation.

To monitor treatment response, tumor volumes were monitored every 2 days after irradiation (Fig. 5c). Fig.5c shows that tumors treated with ACEC and albumin/ECNT without irradiation grew rapidly. Similarly, tumors treated with PBS, albumin/Ce6 and free Ce6 grew rapidly with or without irradiation, suggesting that tumor growth was not influenced by free photosensitizer, albumin/Ce6 or irradiation alone. After irradiation, tumors were ablated in albumin/ECNTand ACEC-treated groups in the first 
6 days after irradiation, indicating that albumin-coated ECNTs could accumulate in tumors. Unfortunately, tumors treated with albumin/ECNTs appeared again 6 days after irradiation because PTT alone was insufficient for tumor eradication; in fact, a tumor remnant was observed (Fig. 5d and e)after PTT due to that uneven PTT effects results in a more significant tumor regrowth[49]. However, PTT and PDT combined and applied to ACEC-treated animals were inhibited and did not reappear during the study by PTT ablated of tumor cells and PDT indcued tumor cell apoptosis[50]. After PTT/PDT treatment, tumors were virtually eradicated (Fig. 5 and S8). However, mice treated with PBS, Ce6, albumin/Ce6 or albumin/ECNT had rapidly growing tumors that were fatal to animals. Mouse body weight after treatment was recorded during the experiment and no obvious differences were noted among groups (Fig. 5f).

In order to verify the tumor accumulation of ACEC, tumor tissue was subjected to raman imaging and found strong G-band in ACEC treated tumors (Fig. S10). No obvious peak at $1590 \mathrm{~cm}^{-1}$ for SWCNT G-band was detected in Ce6 treated group. To confirm the tumor ablation effect from ACEC, tumors received different treatment were collected and subjected to H\&E staining (Fig. 6). In the PBS group, no tumor necrosis occurred and although Ce6 can generate ROS in vitro, tumor cell toxicity was not affected because Ce6 lacks tumor specificity and only accumulates in highly vasular tumors. Thus, this is not sufficient for ROS accumulation and cell death. In albumin/ECNT-treated mice, tumor tissues were initially diminished due to locally high temperatures, but this was insufficent to ablate tumor growth and tumors re-grew days 
later (Fig. 5). Albumin/Ce6- treated mice demonstrated that some tumor necrosis due to ROS, which also insufficient to inhibit tumor growth. Unlike control groups with and without irradiation, obvious karyolysis and necrosis were observed in ACECtreated mice that received radiation (Fig. 6). Several tumor areas had obvious damage after PTT/PDT, suggesting that combined treatment is better for reducing tumors and slowing regrowth. We noted no obvious histological changes in major organs in any animal group (Fig. 6), concluding that ACEC is selectively toxic to tumors and has few side effects in normal organs due to EPR and albumin-mediated active targetability. Although tumor location depth limits photo-penetration for therapeutic purposes, synergistic effects of PTT and PDT may address this limitation because low power optics is sufficient to trigger phototherapy.

\section{Conclusions}

In summary, we described a functional long-circulating SWCNT-based drug delivery system, ACEC, for synsergistic PDT/PTT tumor treatment. With the assistance of EB, we created an SWCNT dispersion formulation and confirmed by FL and PA imaging that the ACEC system was well distributed and accumulated specifically in tumors. The long blood circulatin behavior (48 h) system was found photostable. When ACEC applied for tumor ablation, photothermal therapy was performed after photodynamic therapy to keep the intact of photosensitizer. The optimized phototherapeutic application window guided by FL and PA imaging ablated tumor growth and confirmed 
by MRI data, suggested that PTT and PDT were synergistic and virtually destroyed tumors and prevented regrowth. Overall, ACEC is not acutely toxic and this EB-based drug delivery system is suitable for image-guided synergistic PDT/PTT therapy as well as tumor identification.

Conflict of Interest: The authors declare no competing financial interest.

\section{Acknowledgements}

This work was supported by National Science Foundation of China (NSFC) (Grants No. 51373144, 81201129 and 81471655), the National High Technology Research and Development Program of China (863 Program) (Grant No. 2014AA020708), the Fundamental Research Funds for the Central Universities (Grant No. 20720150064). 


\section{Reference}

[1] T.M. Allen, Ligand-targeted therapeutics in anticancer therapy, Nat Rev Cancer 2 (2002) 750-763.

[2] K. Cho, X. Wang, S. Nie, Z.G. Chen, D.M. Shin, Therapeutic nanoparticles for drug delivery in cancer, Clin Cancer Res 14 (2008) 1310-1316.

[3] G. Mikhaylov, U. Mikac, A.A. Magaeva, V.I. Itin, E.P. Naiden, et al., Ferriliposomes as an MRI-visible drug-delivery system for targeting tumours and their microenvironment, Nat Nanotechnol 6 (2011) 594-602.

[4] K. Bourzac, Nanotechnology: Carrying drugs, Nature 491 (2012) S58-60.

[5] Q. Peng, S. Zhang, Q. Yang, T. Zhang, X.Q. Wei, et al., Preformed albumin corona, a protective coating for nanoparticles based drug delivery system, Biomaterials 34 (2013) 8521-8530.

[6] S. Gao, L. Zhang, G. Wang, K. Yang, M. Chen, et al., Hybrid graphene/Au activatable theranostic agent for multimodalities imaging guided enhanced photothermal therapy, Biomaterials 79 (2015) 36-45.

[7] S.M. Moghimi, A.C. Hunter, J.C. Murray, Long-circulating and target-specific nanoparticles: theory to practice, Pharmacol Rev 53 (2001) 283-318.

[8] P. Aggarwal, J.B. Hall, C.B. McLeland, M.A. Dobrovolskaia, S.E. McNeil, Nanoparticle interaction with plasma proteins as it relates to particle biodistribution, biocompatibility and therapeutic efficacy, Adv Drug Deliv Rev 61 (2009) 428-437.

[9] A.R. Kirtane, J. Panyam, Polymer nanoparticles: Weighing up gene delivery, Nat Nanotechnol 8 (2013) 805-806.

[10] F. Helm, G. Fricker, Liposomal conjugates for drug delivery to the central nervous system, Pharmaceutics 7 (2015) 27-42.

[11] A. Kodiyan, E.A. Silva, J. Kim, M. Aizenberg, D.J. Mooney, Surface modification with alginate-derived polymers for stable, protein-repellent, long-circulating gold nanoparticles, ACS Nano 6 (2012) 4796-4805.

[12] M. Mullner, S.J. Dodds, T.H. Nguyen, D. Senyschyn, C.J. Porter, et al., Size and rigidity of cylindrical polymer brushes dictate long circulating properties in vivo, ACS Nano 9 (2015) 1294-1304.

[13] Z. Sheng, L. Song, J. Zheng, D. Hu, M. He, et al., Protein-assisted fabrication of nano-reduced graphene oxide for combined in vivo photoacoustic imaging and photothermal therapy, Biomaterials 34 (2013) 5236-5243.

[14] J.L. Perry, K.G. Reuter, M.P. Kai, K.P. Herlihy, S.W. Jones, et al., PEGylated PRINT nanoparticles: the impact of PEG density on protein binding, macrophage association, biodistribution, and pharmacokinetics, Nano Lett 12 (2012) 5304-5310. 
[15] H. Dong, N. Dube, J.Y. Shu, J.W. Seo, L.M. Mahakian, et al., Long-circulating 15 nm micelles based on amphiphilic 3-helix peptide-PEG conjugates, ACS Nano 6 (2012) 5320-5329.

[16] A.S. Abu Lila, H. Kiwada, T. Ishida, The accelerated blood clearance (ABC) phenomenon: clinical challenge and approaches to manage, J Control Release 172 (2013) 38-47.

[17] Y. Hashimoto, A.S. Abu Lila, T. Shimizu, T. Ishida, H. Kiwada, B cell-intrinsic toll-like receptor 7 is responsible for the enhanced anti-PEG IgM production following injection of siRNA-containing PEGylated lipoplex in mice, J Control Release 184 (2014) 1-8.

[18] Q. Yang, S.K. Lai, Anti-PEG immunity: emergence, characteristics, and unaddressed questions, Wiley Interdiscip Rev Nanomed Nanobiotechnol 7 (2015) 655677.

[19] L. Cheng, C. Wang, L. Feng, K. Yang, Z. Liu, Functional nanomaterials for phototherapies of cancer, Chem Rev 114 (2014) 10869-10939.

[20] J.U. Menon, P. Jadeja, P. Tambe, K. Vu, B. Yuan, et al., Nanomaterials for photobased diagnostic and therapeutic applications, Theranostics 3 (2013) 152-166.

[21] W.T. Phillips, A. Bao, A.J. Brenner, B.A. Goins, Image-guided interventional therapy for cancer with radiotherapeutic nanoparticles, Adv Drug Deliv Rev 76 (2014) 39-59.

[22] Z. Liu, S.M. Tabakman, Z. Chen, H. Dai, Preparation of carbon nanotube bioconjugates for biomedical applications, Nat Protoc 4 (2009) 1372-1382.

[23] A. Bianco, K. Kostarelos, M. Prato, Applications of carbon nanotubes in drug delivery, Curr Opin Chem Biol 9 (2005) 674-679.

[24] Z. Liu, S. Tabakman, K. Welsher, H. Dai, Carbon Nanotubes in Biology and Medicine: In vitro and in vivo Detection, Imaging and Drug Delivery, Nano Res 2 (2009) 85-120.

[25] T.R. Fadel, F.A. Sharp, N. Vudattu, R. Ragheb, J. Garyu, et al., A carbon nanotubepolymer composite for T-cell therapy, Nat Nanotechnol 9 (2014) 639-647.

[26] A.A. Bhirde, B.V. Chikkaveeraiah, A. Srivatsan, G. Niu, A.J. Jin, et al., Targeted therapeutic nanotubes influence the viscoelasticity of cancer cells to overcome drug resistance, ACS Nano 8 (2014) 4177-4189.

[27] L. Lin, L. Liu, B. Zhao, R. Xie, W. Lin, et al., Carbon nanotube-assisted optical activation of TGF-beta signalling by near-infrared light, Nat Nanotechnol 10 (2015) 465-471.

[28] S. Zhou, Y. Hashida, S. Kawakami, J. Mihara, T. Umeyama, et al., Preparation of immunostimulatory single-walled carbon nanotube/CpG DNA complexes and evaluation of their potential in cancer immunotherapy, Int J Pharm 471 (2014) 214-223. [29] N.W. Kam, H. Dai, Carbon nanotubes as intracellular protein transporters: generality and biological functionality, J Am Chem Soc 127 (2005) 6021-6026.

[30] A. Al Faraj, A.P. Shaik, A.S. Shaik, Magnetic single-walled carbon nanotubes as efficient drug delivery nanocarriers in breast cancer murine model: noninvasive 
monitoring using diffusion-weighted magnetic resonance imaging as sensitive imaging biomarker, Int J Nanomedicine 10 (2015) 157-168.

[31] W. Shao, A. Paul, B. Zhao, C. Lee, L. Rodes, et al., Carbon nanotube lipid drug approach for targeted delivery of a chemotherapy drug in a human breast cancer xenograft animal model, Biomaterials 34 (2013) 10109-10119.

[32] Z. Liu, K. Chen, C. Davis, S. Sherlock, Q. Cao, et al., Drug delivery with carbon nanotubes for in vivo cancer treatment, Cancer Res 68 (2008) 6652-6660.

[33] Z. Liu, J.T. Robinson, S.M. Tabakman, K. Yang, H.J. Dai, Carbon materials for drug delivery \& cancer therapy, Materials Today 14 (2011) 316-323.

[34] L. Zhang, P. Rong, M. Chen, S. Gao, L. Zhu, A novel single walled carbon nanotube (SWCNT) functionalization agent facilitating in vivo combined chemo/thermo therapy, Nanoscale 7 (2015) 16204-16213.

[35] Z. Sheng, D. Hu, M. Zheng, P. Zhao, H. Liu, et al., Smart human serum albuminindocyanine green nanoparticles generated by programmed assembly for dual-modal imaging-guided cancer synergistic phototherapy, ACS Nano 8 (2014) 12310-12322.

[36] H. Jeong, M. Huh, S.J. Lee, H. Koo, I.C. Kwon, et al., Photosensitizer-conjugated human serum albumin nanoparticles for effective photodynamic therapy, Theranostics 1 (2011) 230-239.

[37] G. Wang, F. Zhang, R. Tian, L. Zhang, G. Fu, et al., Nanotubes-Embedded Indocyanine Green-Hyaluronic Acid Nanoparticles for Photoacoustic-Imaging-Guided Phototherapy, ACS Appl Mater Interfaces 8 (2016) 5608-5617.

[38] M. Price, J.J. Reiners, A.M. Santiago, D. Kessel, Monitoring singlet oxygen and hydroxyl radical formation with fluorescent probes during photodynamic therapy, Photochem Photobiol 85 (2009) 1177-1181.

[39] Y. Hashida, H. Tanaka, S.W. Zhou, S. Kawakami, F. Yamashita, et al., Photothermal ablation of tumor cells using a single-walled carbon nanotube-peptide composite, Journal of Controlled Release 173 (2014) 59-66.

[40] A.V. Naumov, S. Ghosh, D.A. Tsyboulski, S.M. Bachilo, R.B. Weisman, Analyzing Absorption Backgrounds in Single-Walled Carbon Nanotube Spectra, Acs Nano 5 (2011) 1639-1648.

[41] H. Kataura, Y. Kumazawa, Y. Maniwa, I. Umezu, S. Suzuki, et al., Optical properties of single-wall carbon nanotubes, Synthetic Metals 103 (1999) 2555-2558.

[42] P.D. Boyer, H. Shams, S.L. Baker, M.R.K. Mofrad, M.F. Islam, et al., Enhanced intracellular delivery of small molecules and drugs via non-covalent ternary dispersions of single-wall carbon nanotubes, Journal of Materials Chemistry B 4 (2016) 1324-1330. [43] Z. Liu, C. Davis, W. Cai, L. He, X. Chen, et al., Circulation and long-term fate of functionalized, biocompatible single-walled carbon nanotubes in mice probed by Raman spectroscopy, Proc Natl Acad Sci U S A 105 (2008) 1410-1415.

[44] Z. Liu, W. Cai, L. He, N. Nakayama, K. Chen, et al., In vivo biodistribution and highly efficient tumour targeting of carbon nanotubes in mice, Nat Nanotechnol 2 (2007) 47-52. 
[45] L. Zhu, G. Niu, X. Fang, X. Chen, Preclinical molecular imaging of tumor angiogenesis, Quarterly Journal of Nuclear Medicine and Molecular Imaging 54 (2010) 291-308.

[46] L. Zhu, J. Xie, M. Swierczewska, F. Zhang, Q. Quan, et al., Real-time video imaging of protease expression in vivo, Theranostics 1 (2011) 18-27.

[47] K. Yang, L. Zhu, L.M. Nie, X.L. Sun, L. Cheng, et al., Visualization of Protease Activity In Vivo Using an Activatable Photo-Acoustic Imaging Probe Based on $\mathrm{CuS}$ Nanoparticles, Theranostics 4 (2014) 134-141.

[48] J.R. Lepock, Cellular effects of hyperthermia: relevance to the minimum dose for thermal damage, Int J Hyperthermia 19 (2003) 252-266.

[49] D.C. Bloch, J.S. Oghalai, R.K. Jackler, M. Osofsky, L.H. Pitts, The fate of the tumor remnant after less-than-complete acoustic neuroma resection, Otolaryngol Head Neck Surg 130 (2004) 104-112.

[50] J. Wang, L. Zhang, M. Chen, S. Gao, L. Zhu, Activatable Ferritin Nanocomplex for Real-Time Monitoring of Caspase-3 Activation during Photodynamic Therapy (PDT), ACS Appl Mater Interfaces (2015). 


\section{FIGURE LEGENDS}

Scheme 1. Preparation and application of albumin/Ce6 fabricated EB/carbon nanotubebased delivery system (ACEC).

Fig. 1. Characterizations of ACEC. a) UV-vis spectra of functionalized SWCNTs. Insert is TEM of ACEC. b) UV-vis spectrum of ACEC in PBS. The insert images show the stability of ACEC in DMEM, FBS, PBS, and water. c) Fluorescence intensity of free Ce6 and ACEC. No obvious fluorescent quenching was observed. d) Photoacoustic signals of Ce6 and ACEC. Inserted is PA imaging of Ce6 and ACEC.

Fig. 2. Cellular uptake and intrinsic cytotoxicity of ACEC. (a) SCC-7 cells uptake of Ce6 $(50 \mu \mathrm{g} / \mathrm{mL}$ ), Albumin/Ce6 (contains $50 \mu \mathrm{g} / \mathrm{mL}$ Ce6) and ACEC (contains 50 $\mu \mathrm{g} / \mathrm{mL}$ Ce6) after $6 \mathrm{~h}$. Scale bars, $10 \mu \mathrm{m}$. (b) Time dependent photothermal effect of ACEC, Albumin/Ce6, Ce6 and PBS with laser irradiations. (c) ROS generation of ACEC at different concentration upon $630 \mathrm{~nm}$ laser irradiation for $5 \mathrm{~min}$. (d) Cell viability of SCC-7 cells after ACEC treatment under different conditions. 
Fig. 3. Blood circulation of functionalized ACEC.

Fig.4. In vivo fluorescence imaging and photoacoustic imaging (PA) imaging of SCC7 tumor. (a) In vivo fluorescence images of mice intravenously administrated with free Ce6, Albumin/Ce6 and ACEC at $100 \mu \mathrm{g} \mathrm{Ce} 6$ concentration $(5 \mathrm{mg} / \mathrm{kg})$ at different time intervals. Arrows indicate the tumor site. (b) Signal intensity of tumors treated with free Ce6, Albumin/Ce6 and ACEC at different time intervals (tumor/Muscle ratio). (c) In vivo photoacoustic images of mice intravenously administrated with free Ce6 and ACEC at $100 \mu \mathrm{g}$ Ce6 concentration $(5 \mathrm{mg} / \mathrm{kg}$ ) at different time intervals. (d) Signal intensity of tumors treated with free $\mathrm{Ce} 6$ and $\mathrm{ACEC}$ at different time intervals (PA/ PA 0 ratio).

Fig.5. In vivo PDT/PTT ablation of tumor. (a) Thermal images of SCC-7 tumor-bearing mice exposed to $630 \mathrm{~nm}$ laser for $10 \mathrm{~min}$ and subsequently $808 \mathrm{~nm}$ laser for $15 \mathrm{~min}$. (b) Heating curves of tumors treated with different particles. (c) Tumor growth curves of mice received different treatments. $(* * *) p<0.001$. d) Body weights of mice received different treatments. (d) MRI images of mice treated with different materials after laser irradiation at different time points. (e) Tumor volume measured by MRI. (f) Body weight changes of mice received different treatments.

Fig. 6. Histology of tumor mice received different treatments. Hematoxylin and eosin $(\mathrm{H} \& \mathrm{E})$ staining of tumors and primary organs in mice treated with ACEC, albumin- 
ECNTs, free Ce6, albumin/Ce6, PBS with or without $630+808 \mathrm{~nm}$ NIR irradiation at $24 \mathrm{~h}$ post-treatment. Scale bar: $100 \mu \mathrm{m}$.

\section{Scheme 1}



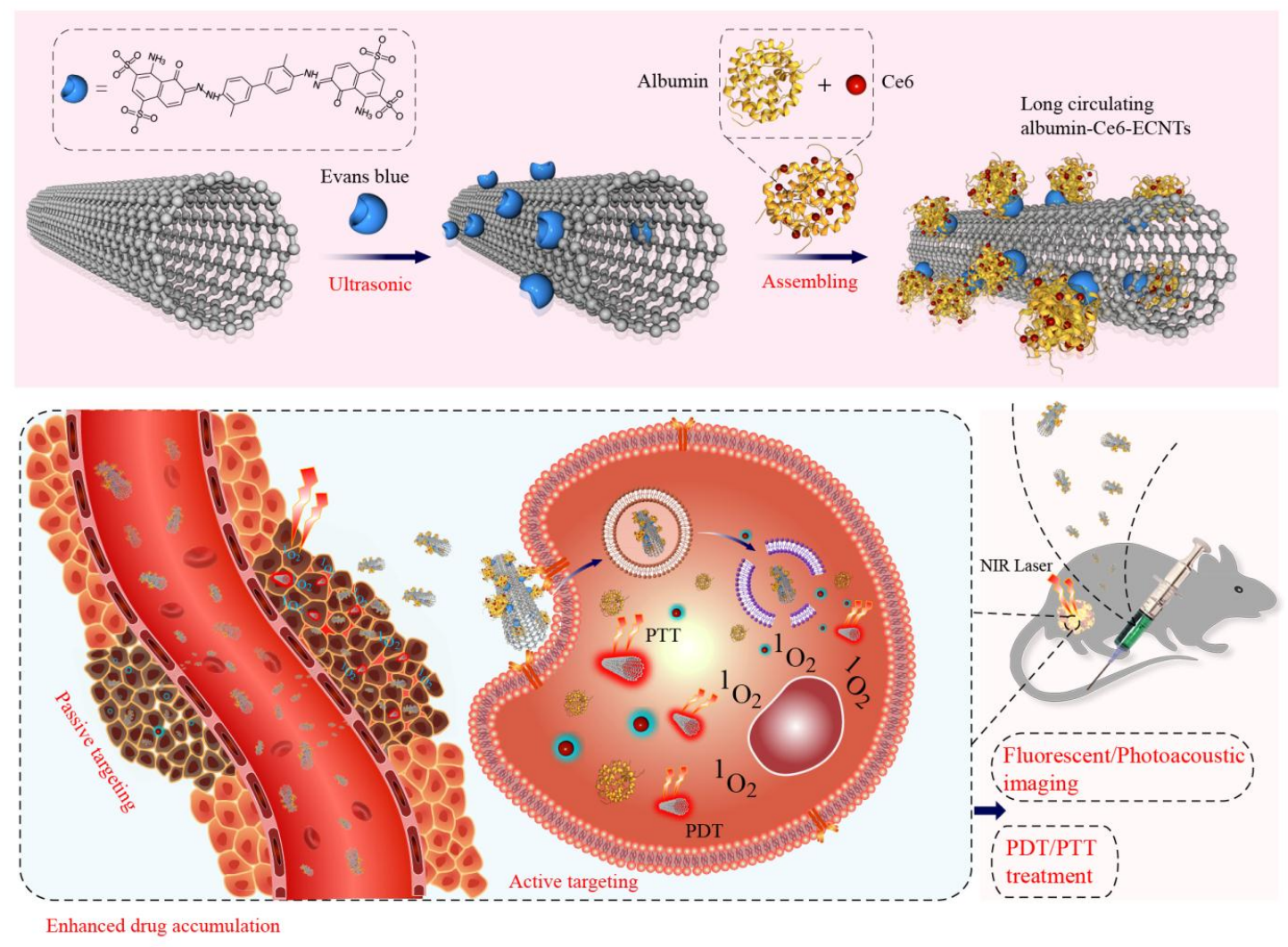

\section{Fig. 1}


a

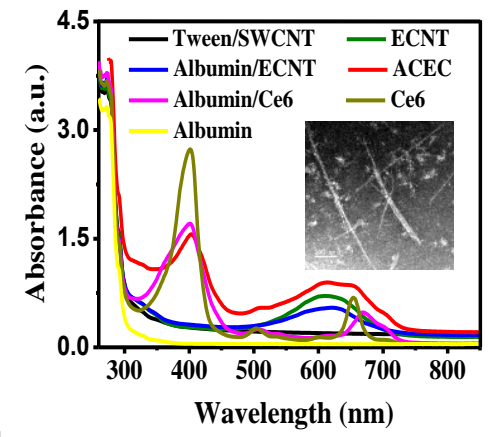

C

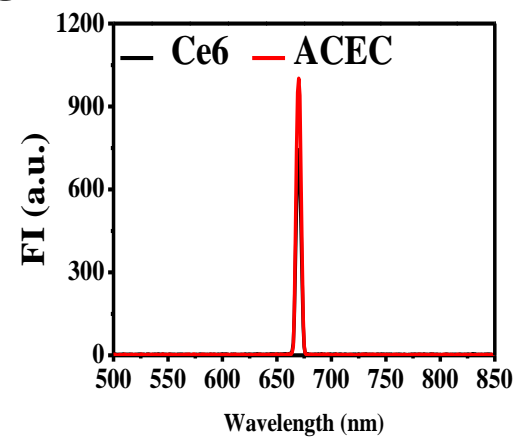

b

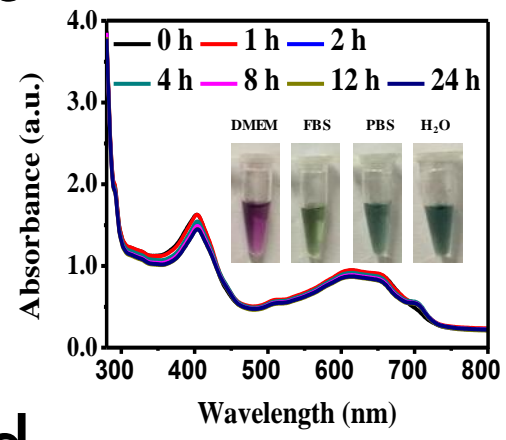

0

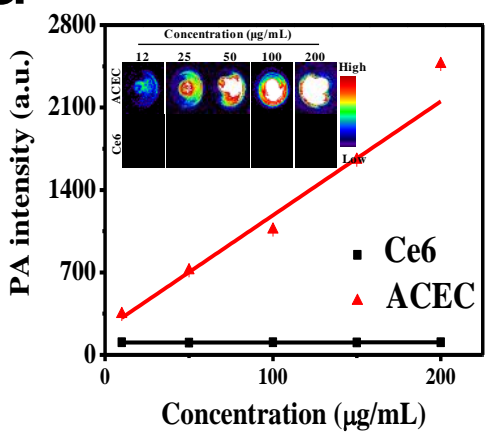


Fig. 2
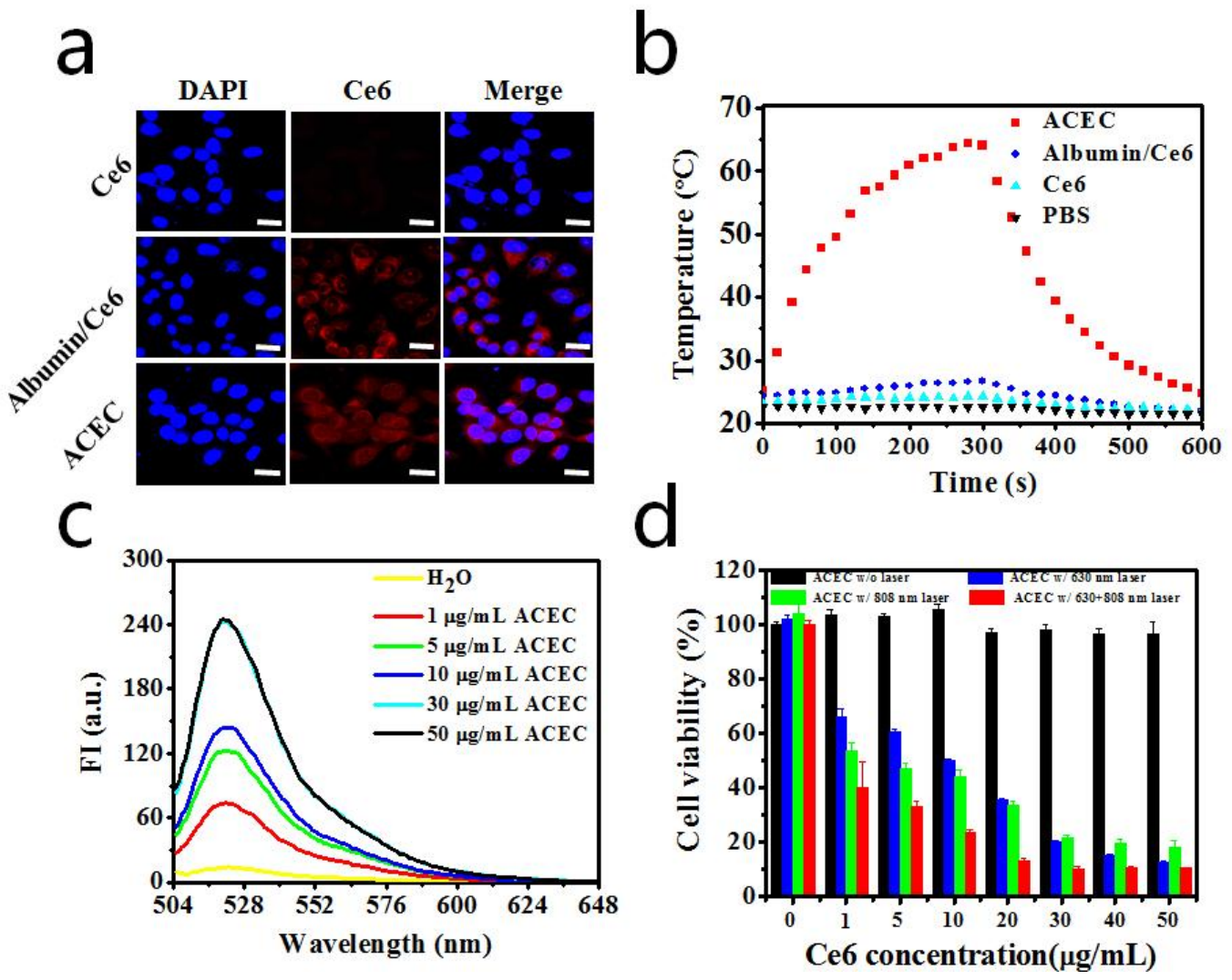
Fig. 3

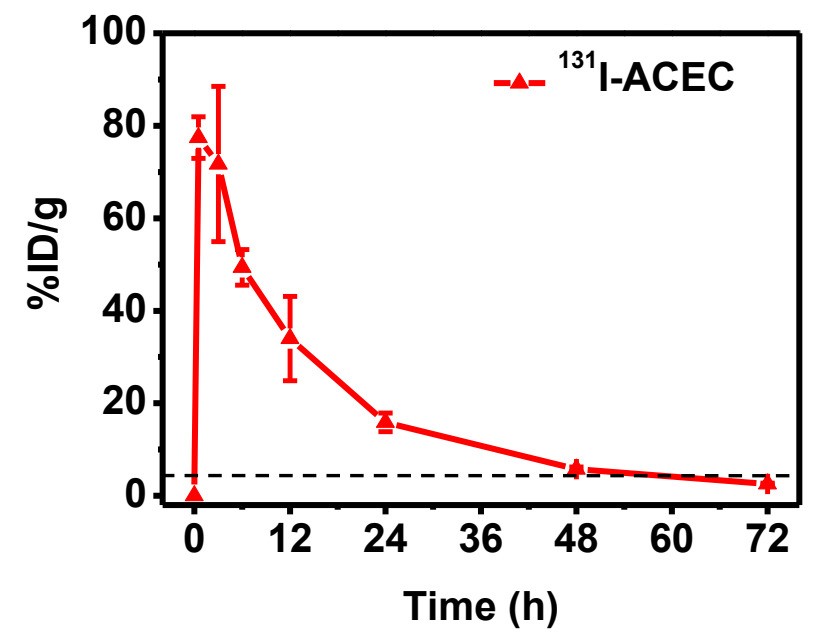

Fig. 4 


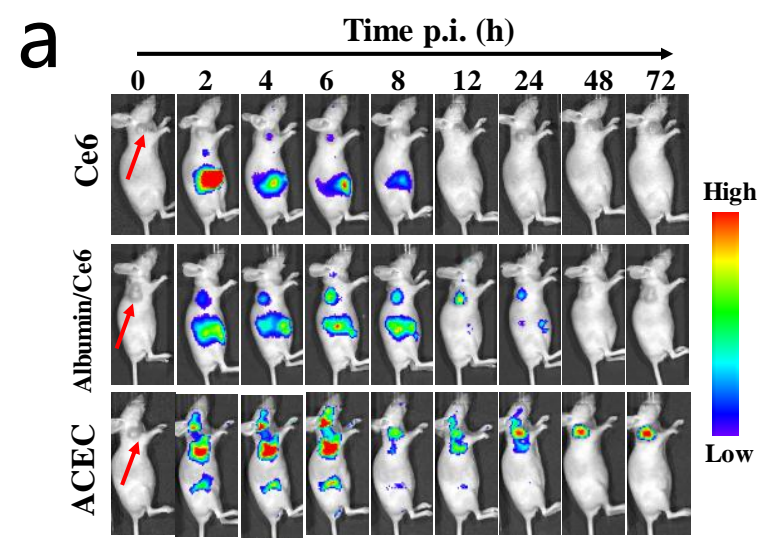

b

C
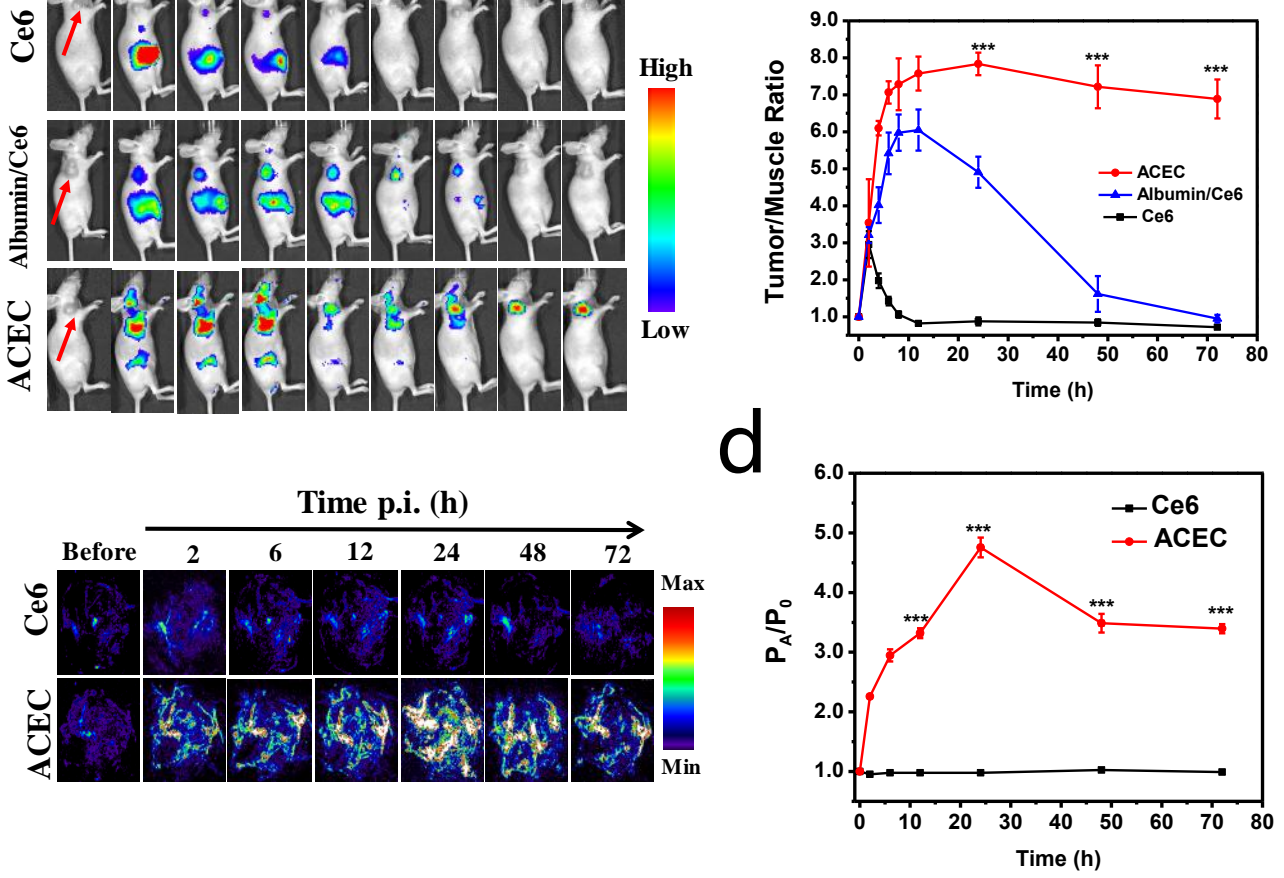
Fig. 5

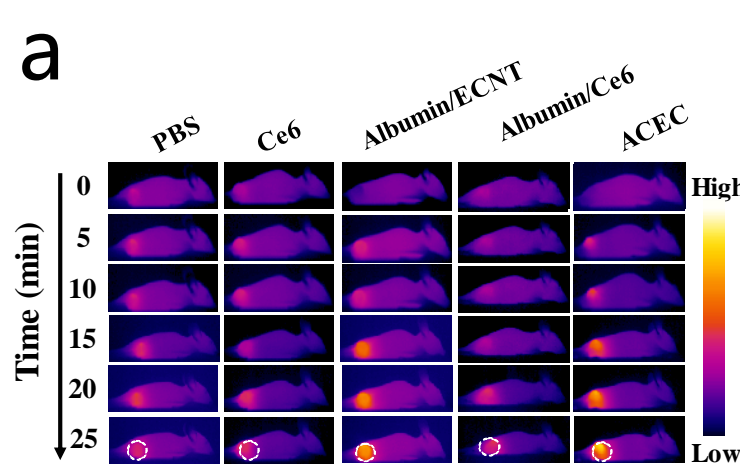

b

C
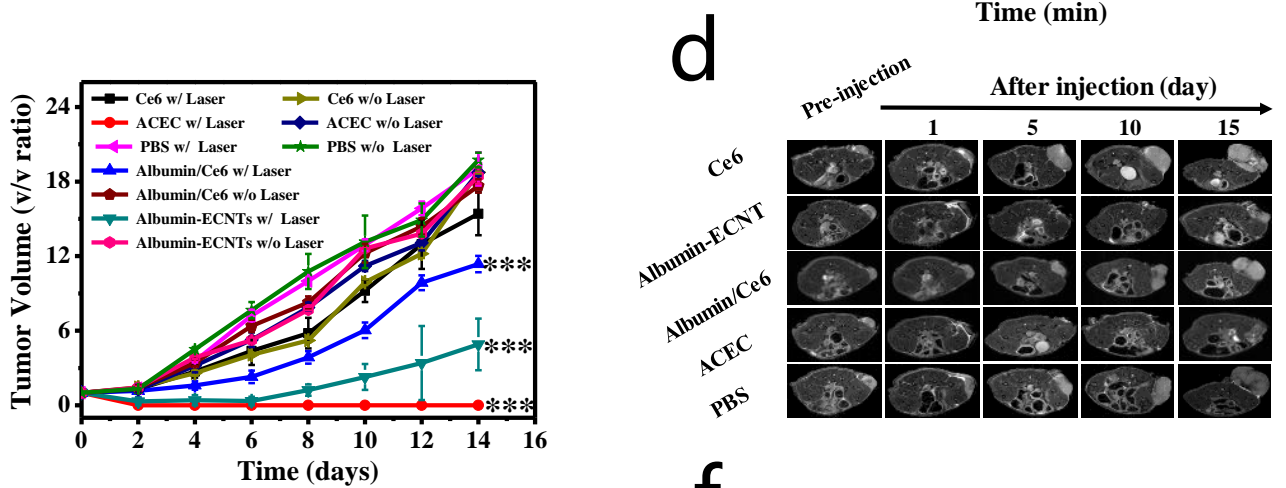

e

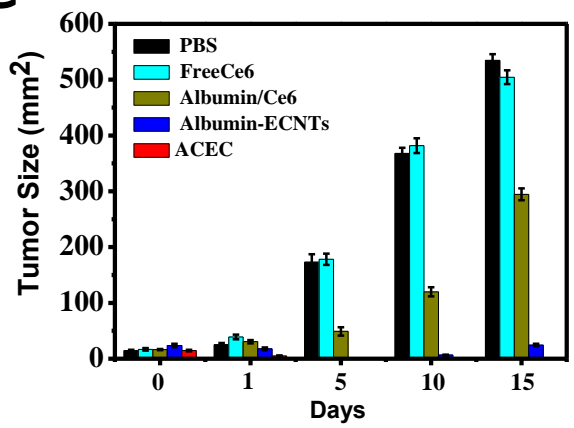

$f$
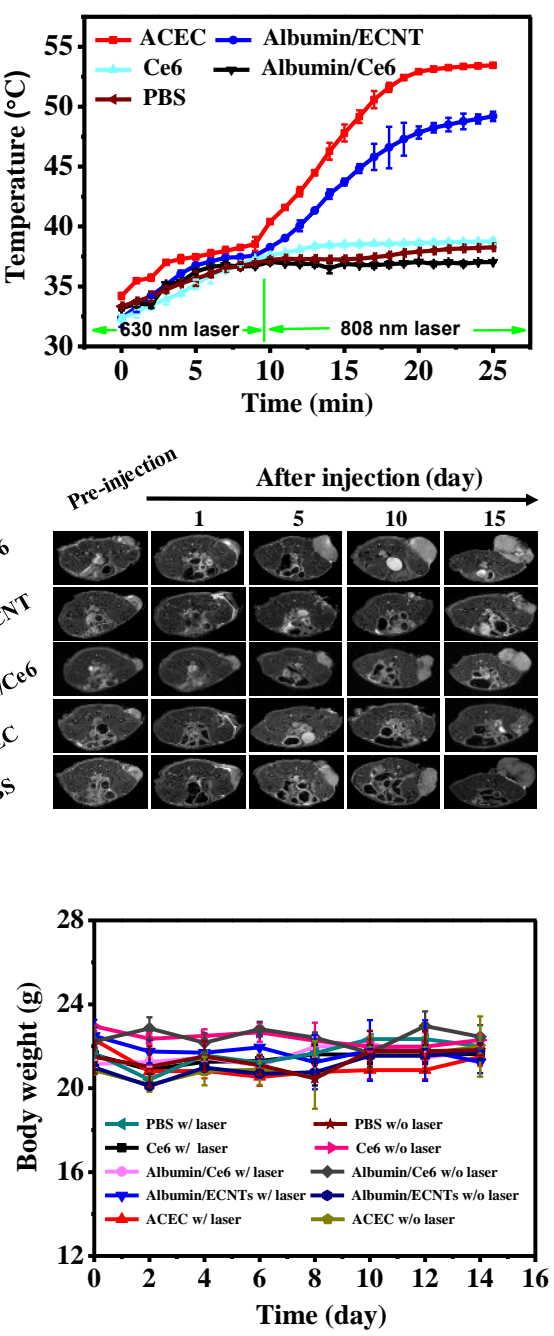
Fig. 6

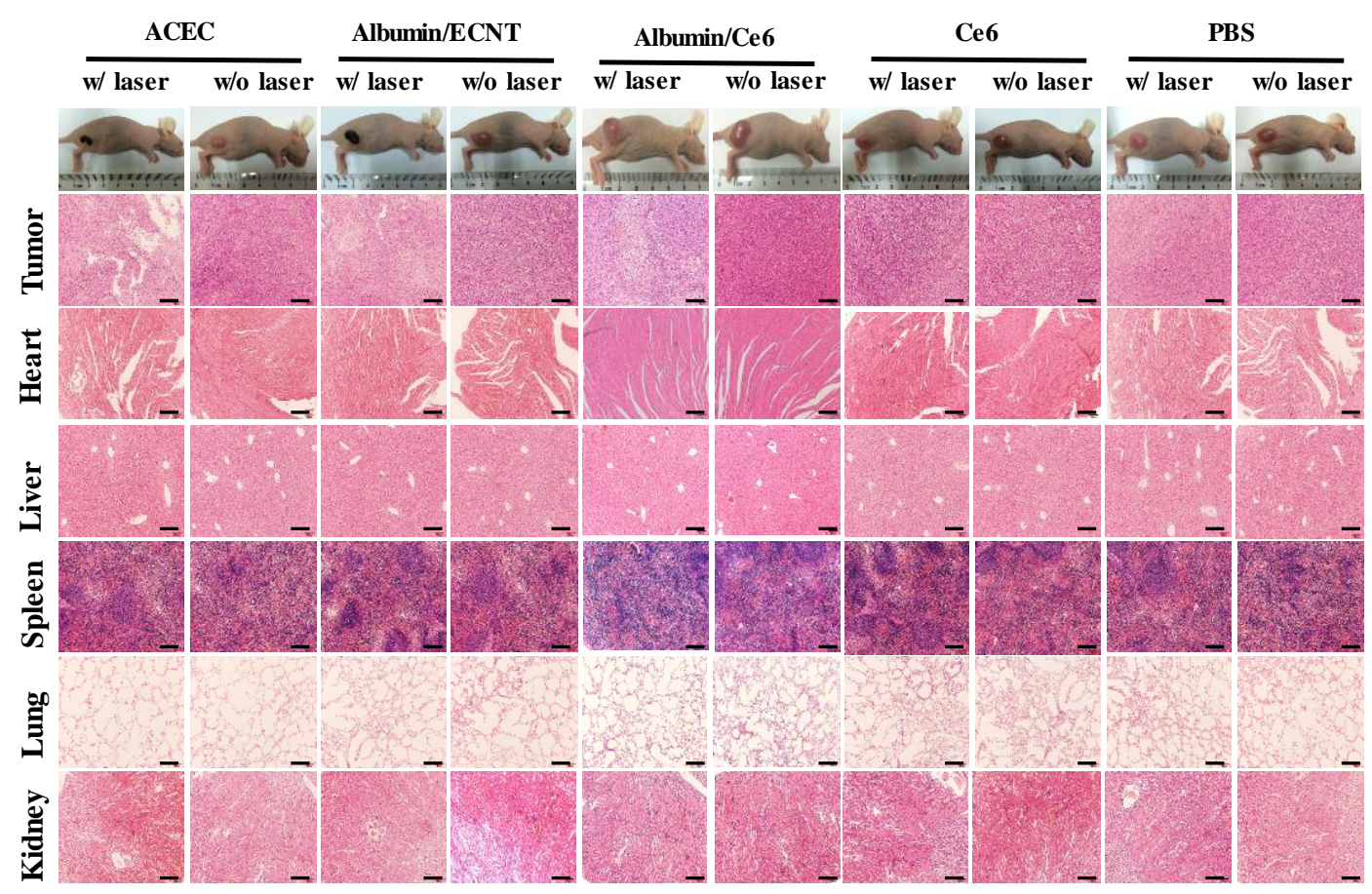


Table 1. The loading efficiency of albumin/Ce6 on ECNT

\begin{tabular}{|c|c|c|}
\hline Albumin-Ce6 : ECNT & content $(\%)$ & loading efficiency (\%) \\
\hline $3: 2$ & 29.0 & 72.5 \\
\hline $1: 4$ & 16.2 & 81 \\
\hline $1: 9$ & 7.03 & 70.3 \\
\hline
\end{tabular}

